\title{
Integration of Decision Support Modules to Identify the Priority of Risk of Failure in Topside Piping Equipment: An Industrial Case Study from the NCS
}

\author{
A.M.N.D.B. Seneviratne and R.M. Chandima Ratnayake \\ University of Stavanger, Stavanger, Norway \\ \{chandima.ratnayake, dammika.seneviratne\} @uis.no
}

\begin{abstract}
The identification and prioritization of locations that have potential for failure (also referred to as thickness measurement locations (TMLs)) in the in-service inspection planning of offshore topside piping equipment requires a significant amount of data analysis together with relevant information. In this context, planning personnel analyze data and information retrieved from piping inspection databases through enterprise resource planning (ERP) software to investigate possible degradation trends in order to recognize the TMLs that have reached a critical level. It is observed that suboptimal prioritization occurs due to time restriction vs. amount of data and/or information that has to be evaluated. The suboptimal prioritization omits some of the critical TMLs, increasing the risk of failures whilst also increasing cost due to taking non-critical TMLs into inspection. Therefore, this manuscript illustrates an approach to integrate the decision support modules (DSMs) via an artificial neural network model for the optimum prioritization.
\end{abstract}

Keywords: In-service inspection planning, topside piping equipment, decision support modules, thickness measurement locations, artificial neural networks, ERP software.

\section{Introduction}

DSMs are used in the identification of possible failure locations in offshore topside piping equipment. The base of most DSMs is empirical engineering analysis of systems/equipment. The identification of possible failure location (TMLs) is a major part of inspection planning in offshore oil and gas production and process facilities (OO\&G P\&PFs) (Ratnayake and Markeset, 2010). Inspection planning is one of the key elements in maintaining the technical integrity of aging offshore production and process facilities (OP\&PFs) (Ratnayake, 2012a). Standards, for instance Norsok Z-008, DNV RP-G101 and API 581, guide the operators and authorities in carrying out and maintaining inspection activities according to the rules and regulations defined by the governing authorities (Norsok Z-008, 2011; DNV RP G101, 2010; API 581, 2008). 
Inspection planning is an essential task in maintaining asset integrity at a predefined level in OP\&PFs (Ratnayake, 2012c). In particular, of the process equipment in the OP\&PFs, topside piping equipment, for instance, piping, valves, tanks, etc., undergoes in-service inspections to maintain the required health, safety, environment and quality (HSE\&Q) limits imposed by the regulatory authorities on the Norwegian continental shelf (NCS) (Ratnayake, 2012b). The large amount of historical data and information is analyzed during the in-service inspection planning process, mainly to identify the critical TMLs for inspections (Ratnayake, 2013). The data is analyzed by field experts who have gathered experience in the inspection planning field for numerous years. The data is analyzed considering different scenarios (perspectives). For instance, the corrosion trends, erosion trends, fluid flow variations (turbulences) are considered in identifying the critical TMLs (Ratnayake et al., 2011). Therefore, DSMs developed to identify corrosion trends, flow patterns, etc., are helpful for the inspection planning personnel in identifying the critical TMLs.

Researchers have developed different degradation prediction models for hydrocarbon piping, which use corrosion and erosion empirical formulae. For instance, Nesic (2007), Nesic et al. (2009) and Norsok M-506 (2005) have developed a number of corrosion models for the use of hydrocarbon piping equipment for production and process facilities. Furthermore, erosion models developed in DNV RP O501 (2007) are used in the industry to identify erosive locations. The stress identification models are important in the identification of the wall thinning and crack propagation of equipment (Alvarado et al., 2007). Flow pattern identification models are also important in recognizing the critical vortexes developed inside the equipment under the multiphase flow, which generate erosion corrosion (Valle, 1998; Ferre et al., 1996). Moreover, Srinivasan et al. have developed a risk analysis model based on possible corrosion in petrochemical piping equipment (Srinivasan and Sueth, 2011). A DSM, which evaluates the risk level of TMLs based on the technical condition, has been developed by Seneviratne and Ratnayake (2013). However, there is limited use of the above models in the inspection planning field in identification of critical TMLs.

Within the industry, owner/operator specific software modules are used for recording and storing the piping and degradation data and information (Ratnayake, 2012a). Moreover, some of these modules are used for the basic analysis of the degradation rates of TMLs based on the measurements carried out in the field. The linking of the DSMs for the identification of the critical TMLs to the basic ERP software modules, for instance SAP, RIS etc., will improve the quality of recommendation regarding critical equipment for the inspections.

The ERP based software offers flexibility in integrating other software modules (Kahkonen and Smolander, 2013). The use of DSMs is specific to the particular industrial case in which it is used and special attention is needed in integrating into a common ERP system. Kahkonen and Smolander (2013) have surveyed the development of the integration of DSMs into ERP systems and have stated that the integration must be work specific. Therefore, the manuscript suggests a methodology for integrating the DSMs used in the inspection planning process into the existing ERP systems in the in-service inspection planning of offshore topside piping equipment using artificial neural networks (ANNs). 
The ANN is greatly used in data prioritization applications. ANN applications are used by Knapp and Wang (1992) and Becraft and Lee (1993) in manufacturing industries for prioritizing failures. Knapp and Wang (1992) used the ANNs for the recognition and prioritization of failure propagation by employing fluctuated data. Becraft and Lee (1993) developed a system using ANNs for fault diagnosis in chemical process plants under high risks. However, ANNs have relatively less use in the O\&G industry for prioritizing purposes. The use of an ANN in this study is for the replacement of human judgment. The ANN model prioritizes the critical TMLs according to the criticality given by the DSMs. The ANN models try to imitate the inspection planner and analyze the prioritization like humans. The suggested neural network approach will be a very suitable method for replacing the humans involved in the prioritization system for TMLs. The background of the problem is illustrated in Section 2 of the manuscript, while the methodology is explained in Section 3. System development is explained in Sections 4 and Section 5 presents the concluding remarks.

\section{Background}

The current in-service inspection planning processes for OP\&PFs involve several techniques, used worldwide, which are standardized by different standardization organizations. One of the widely used methods is risk based inspection (RBI), which is explained in the standards, for instance, API (2002, 2008) and DNV (2010).

After the risk assessment (based on RBI) for the equipment in the plant, inspection, test, maintenance and modification activities are planned based on the plants' historical and condition monitoring data. The inspection or maintenance plans reflects the risk (probability and consequence) of the equipment which tends to fail and the philosophy to maintain the fitness of equipment for service by detecting, preventing, controlling and mitigating. The condition of equipment is identified after inspections and necessary actions are taken for maintenance/modifications or re-inspections, if the equipment is not fit for the service.

The inspection planning process consists of several steps. The overall outcome of the inspection planning process is to identify the TMLs for inspections, allocate resources for inspections, and record the measurements and analysis of measurements for further evaluations. Furthermore, a quality inspection program aims to reduce plant downtime, minimize the cost and increase the effectiveness of the inspections.

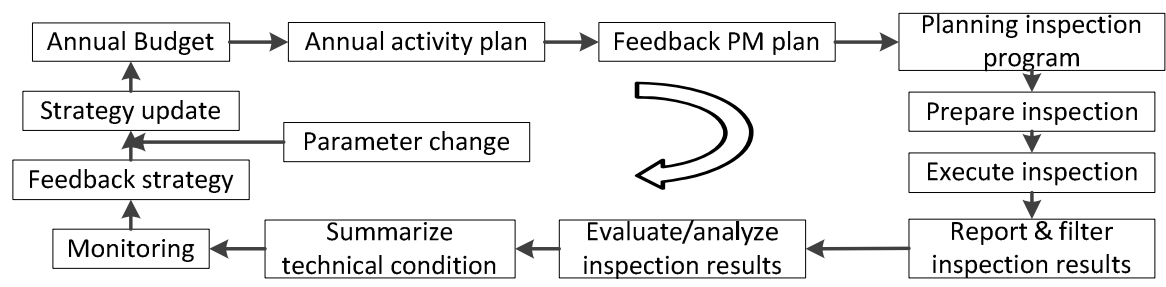

Fig. 1. Inspection planning process 
The inspection planning process discussed above consists of the analysis of a vast amount of data with field experience in the identification of possible TMLs for inspections. The data and information are retrieved from condition monitoring systems, field measurements and standards. The TML analysis is performed by considering the historical thickness measurement data, degradation rates, potential degradation locations and potential failure locations. Therefore, the identification and prioritization of critical TMLs in a subsystem is a major part of the inspection planning process, as illustrated in figure 1 (Ratnayake, 2012b).

In handling and recording data, most of the piping inspection data bases (PIDBs) use the tag number or functional location, which is a number given to the specific equipment in a plant subsystem (Ratnayake, 2014). The system, subsystem and equipment (tag/functional location) numbering is illustrated in the industrial standards, for instance, DNV-RP-G101 (2010). The tag/functional location hierarchy is illustrated in figure 2. The data, for instance measurements from NDE equipment, trend analysis, equipment drawings, pictures, documents, data files and videos, are stored in PIDBs under the tag/functional location number.

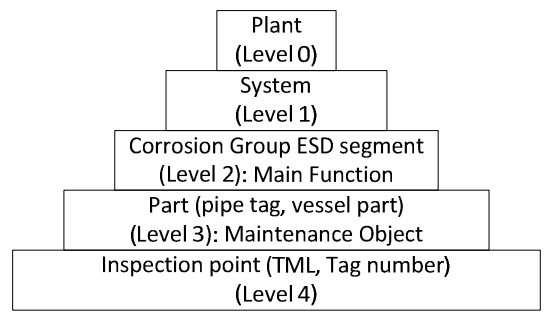

Fig. 2. Equipment level hierarchy

In aging OP\&PFs, due to the effects of years of operational process cycles, the risk level of the plant equipment varies and the initial RBI assessments change over time. Therefore, inspection planning personnel use their experience and knowledge of the flow conditions and equipment condition to identify and prioritize the critical TMLs for inspection planning. This approach is on an ad hoc basis, and the quality of TML prioritization depends on the expertise of the planning personnel. Therefore, this manuscript discusses the utilization and integration of DSMs, for instance degradation prediction models, flow condition models, technical condition models, etc., using ANN to prioritize the critical TMLs for inspection planning purposes.

\section{$3 \quad$ Methodology}

The OP\&PFs have a number of systems which are grouped into subsystems. In a subsystem there are number of pieces of equipment degraded as a result of different degradation mechanisms. The identified degradation mechanisms are empirically modeled by different researchers and industrialists. Most of these degradation models 
are formed as DSMs to identify the critical TMLs in the subsystem. Each DSM prioritizes the TMLs based on its empirical formula. By applying different DSMs, a different prioritization rank of TMLs is obtained. In current industrial practice, field experts make the final cumulative prioritization using their expertise and knowledge. Therefore, for a proper cumulative prioritization, a deployment of prioritization mechanisms is needed. The artificial intelligence techniques are appropriate in representing human knowledge in the prioritization process. Therefore, in this study an ANN (trained multilayer perceptron) model is proposed to obtain the cumulative prioritization to discover the critical TMLs in a subsystem. The method is shown in figure 3.

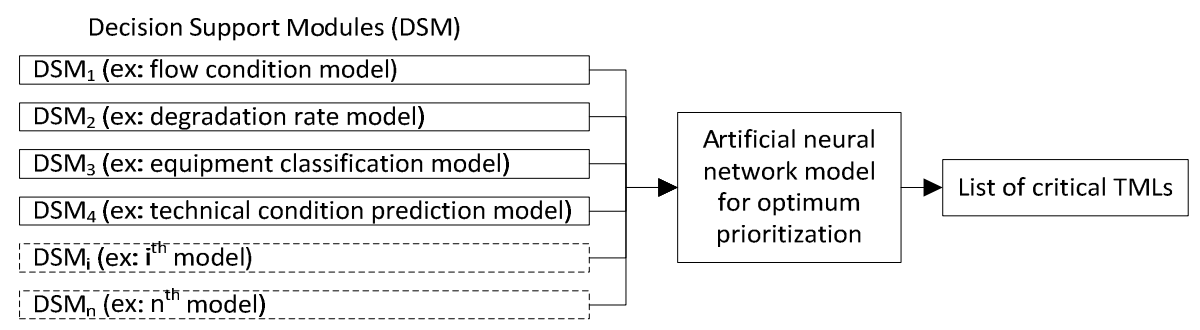

Fig. 3. ANN model for cumulative TML prioritization

\subsection{Decision Support Modules}

DSMs are used in the O\&G industry for various purposes, especially the analysis and identification of critical TMLs. By using the DSMs in the inspection planning process, the TMLs are prioritized according to criticality. The prioritization of TMLs in a system by a selected number of DSMs is shown in figure 3. The individual prioritizations of the DSMs are analyzed by the experts to identify the critical TMLs. In this process the experts prioritize the DSMs' outcome, according to the significance of the importance of the decision support module. Then the most significant decision support module outcome is analyzed for TML prioritization. Moreover, by evaluating all the outcomes of the DSMs, a cumulative prioritization of the TMLs is made for the recommendation of the optimum prioritization of possible failure of TMLs. An example of TMLs of a subsystem prioritized according to the individual decision support module and the decision support module prioritization is shown in Table 01.

The DSM prioritization numbers are: $\mathrm{P}_{\mathrm{DMS} 1}, \mathrm{P}_{\mathrm{DMS} 2}, \mathrm{P}_{\mathrm{DMS} 3}, . ., \mathrm{P}_{\mathrm{DMSi}}, . ., \mathrm{P}_{\mathrm{DMSn}}$. In an application, the DSM prioritization numbers are to be assigned with real numbers according to the reflection of the field experts. $n$ is the maximum number of DSMs used for the prioritization of TMLs in the subsystem.

The TML prioritization numbers are: $\mathrm{P}_{1 \mathrm{j}}, \mathrm{P}_{2 \mathrm{j}}, \mathrm{P}_{3 \mathrm{j}}, \ldots, \mathrm{P}_{\mathrm{ij}}, \ldots, \mathrm{P}_{\mathrm{nj}}$,

$\mathrm{DSM}_{\mathrm{i}}=\mathrm{i}^{\text {th }}$ DSM number; Inspection point $\mathrm{j}=\mathrm{j}^{\text {th }}$ inspection point (TML) number.

The prioritization from the DSM for each inspection point (TML) has been assigned according to the total number of inspection points in the system or on a ranking weight basis (based on the risk levels of TMLs). 
Table 1. TML prioritization by DSM and DSM prioritization

\begin{tabular}{|c|c|c|c|c|c|}
\hline & 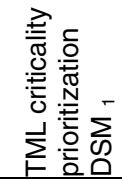 & 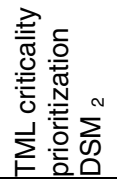 & 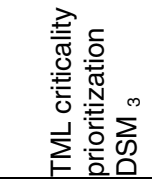 & 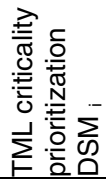 & 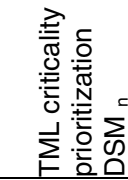 \\
\hline DSM prioritization & $\mathrm{P}_{\mathrm{DMS} 1}$ & $\mathrm{P}_{\mathrm{DMS} 2}$ & $\mathrm{P}_{\mathrm{DMS3}}$ & $P_{\mathrm{DMSi}}$ & $P_{\text {DMSn }}$ \\
\hline \multicolumn{6}{|l|}{ TML number } \\
\hline Inspection point 1 & $P_{11}$ & $P_{21}$ & $P_{31}$ & $P_{\mathrm{i} 1}$ & $P_{n 1}$ \\
\hline Inspection point 2 & $\mathrm{P}_{12}$ & $P_{22}$ & $\mathrm{P}_{32}$ & $\mathrm{P}_{\mathrm{i} 2}$ & $\mathrm{P}_{\mathrm{n} 2}$ \\
\hline Inspection point 3 & $\mathrm{P}_{13}$ & $\mathrm{P}_{23}$ & $\mathrm{P}_{33}$ & $\mathrm{P}_{\mathrm{i} 3}$ & $\mathrm{P}_{\mathrm{n} 3}$ \\
\hline$\ldots$ & $\ldots$ & $\ldots$ & $\ldots$ & $\ldots$ & $\ldots$ \\
\hline Inspection point j & $P_{1 j}$ & $P_{2 j}$ & $P_{3 j}$ & $\mathrm{P}_{\mathrm{ij}}$ & $P_{n j}$ \\
\hline$\ldots$ & $\ldots$ & $\ldots$ & $\ldots$ & $\ldots$ & $\ldots$ \\
\hline Inspection point $\mathrm{n}$ & $P_{1 n}$ & $\mathrm{P}_{2 n}$ & $P_{3 n}$ & $P_{\text {in }}$ & $\mathrm{P}_{\mathrm{nn}}$ \\
\hline
\end{tabular}

\subsection{Use of Artificial Neural Networks in TML Prioritizing}

In this proposed methodology, a prediction model is developed using the ANN technique and applied to the prioritized TML ranking from the DSMs to obtain a cumulative prioritization. The literature provides a number of different ANN architectures in the prioritization applications. Different types of neural networks are synthesized and, according to the research objectives, a multilayer feed forward ANN is used in this research study. The input value for each node of the ANN model will be $\left(\mathrm{P}_{\mathrm{ij}}, \mathrm{P}_{\mathrm{DMSi}}\right)$. The output of the ANN model will be $\mathrm{PC}_{\mathrm{ANNj}}$ where $\mathrm{PC}_{\mathrm{ANNj}}$ is the cumulative prioritization number for the inspection point (TML) $\mathrm{j}$.

\section{Development of the Proposed Model}

A subsystem in one of the matured OP\&PFs is selected and the possible degradation mechanisms are identified to select the needed DSMs. The steps for the development, theoretical testing and validation of the proposed model are as follows: 1). Identify the subsystem degradation trends and failure mechanisms to select DSMs for identifying critical TMLs; 2). Obtain the experts' view on prioritization of TMLs and DSMs; 3). Build a priority list of TMLs and the DSMs with the view of the experts; 4.) Define the multilayer feed forward perceptron ANN model with the appropriate number of nodes (similar to DSMs used) and one hidden layer to replace the field experts' decisions; 5.) Define training data for the neural network from the experts' prioritization on TMLs and DSMs; 6.) Generate the test data for the neural network by running each DSM individually on the subsystem to prioritize the TMLs; 7.) Train and test the neural network and validate the results.

The total structure of the proposed model is illustrated in figure 4. 


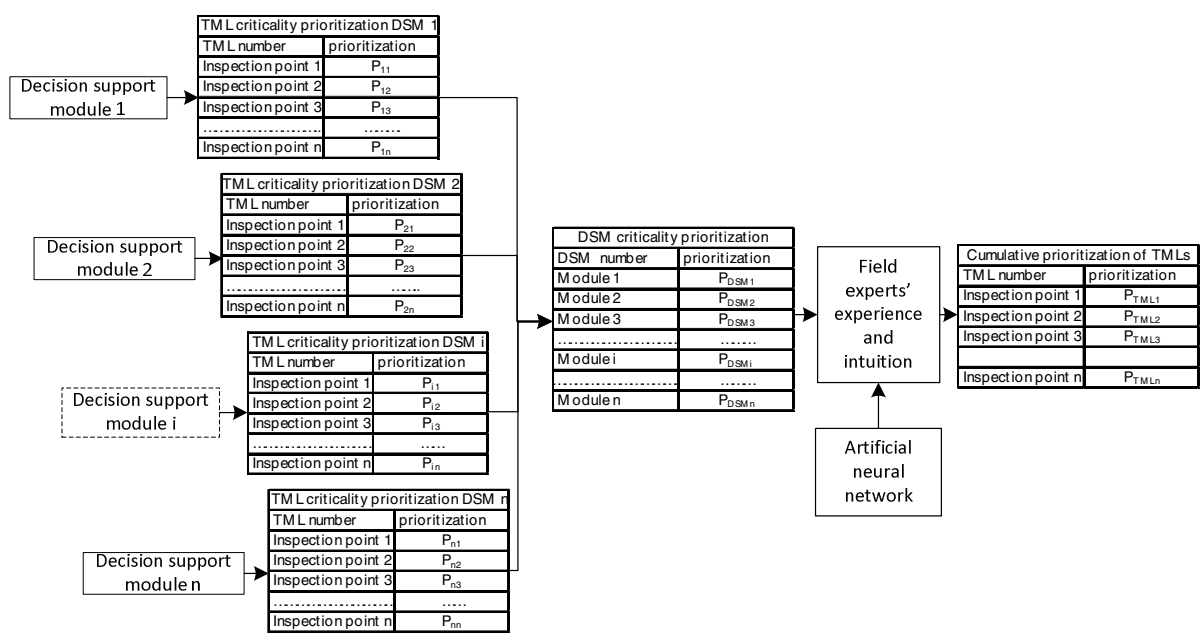

Fig. 4. Functional structure of the proposed model

The outputs from the DSMs for each inspection point (TML) have been ranked in a local manner (The ranking is based on the risk level of the TML. For instance, Seneviratne and Ratnayake (2013) ranked the TMLs according to the risk level based on the technical condition) and fed in to the trained ANN model with the criticality prioritization of the DSMs. A layout of tentative comparison is shown in Table 02.

$\mathrm{PC}_{\mathrm{FEj}}$ : Cumulative prioritization of $\mathrm{j}^{\text {th }}$ inspection point (TML) by field expert

$\mathrm{PC}_{\mathrm{ANNj}}$ : Cumulative prioritization of $\mathrm{j}^{\text {th }}$ inspection point (TML) by ANN model

Table 2. Tentative layout of the comparison of ANN model output and field experts' outcome

\begin{tabular}{|c|c|c|c|c|c|c|c|}
\hline TML number & 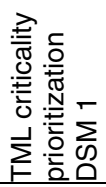 & 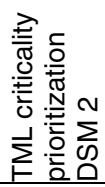 & 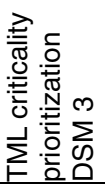 & 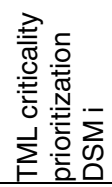 & 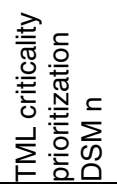 & 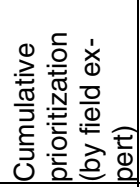 & 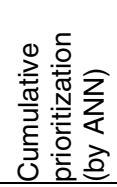 \\
\hline Inspection point 1 & $P_{11}$ & $P_{21}$ & $\mathrm{P}_{31}$ & $\mathrm{P}_{\mathrm{i} 1}$ & $\mathrm{P}_{\mathrm{n} 1}$ & $\mathrm{PC}_{\mathrm{FE} 1}$ & $\mathrm{PC}_{\mathrm{ANN} 1}$ \\
\hline Inspection point 2 & $P_{12}$ & $\mathrm{P}_{22}$ & $\mathrm{P}_{32}$ & $\mathrm{P}_{\mathrm{i} 2}$ & $\mathrm{P}_{\mathrm{n} 2}$ & $\mathrm{PC}_{\mathrm{FE} 2}$ & $\mathrm{PC}_{\mathrm{ANN} 2}$ \\
\hline Inspection point 3 & $P_{13}$ & $\mathrm{P}_{23}$ & $\mathrm{P}_{33}$ & $\mathrm{P}_{\mathrm{i} 3}$ & $P_{n 3}$ & $\mathrm{PC}_{\mathrm{FE} 3}$ & $\mathrm{PC}_{\mathrm{ANN} 3}$ \\
\hline$\ldots$ & $\ldots$ & $\ldots$ & $\ldots$ & $\ldots$ & $\ldots$ & $\ldots$ & $\ldots$ \\
\hline Inspection point j & $P_{1 j}$ & $P_{2 j}$ & $P_{3 j}$ & $P_{i j}$ & $P_{n j}$ & $\mathrm{PC}_{\mathrm{FEj}}$ & $P_{\text {ANNj }}$ \\
\hline & $\ldots$ & $\ldots$ & $\ldots$ & $\ldots$ & $\ldots$ & $\ldots$ & $\ldots$ \\
\hline Inspection point $\mathrm{n}$ & $P_{1 n}$ & $P_{2 n}$ & $P_{3 n}$ & $P_{\text {in }}$ & $P_{n n}$ & $\mathrm{PC}_{\mathrm{FEn}}$ & $\mathrm{PC}_{\text {ANNn }}$ \\
\hline
\end{tabular}

\section{$5 \quad$ Concluding Remarks}

The proposed ANN model is suitable for identifying the critical TMLs in a subsystem which is undergoing different degradation trends and flow condition scenarios. The DSMs developed for degradation, flow condition and failure identification of the 
static mechanical systems under various production and process conditions give different prioritizations. In a real-world situation, field experts analyze the outcome of the different DSMs and identify the critical TMLs for inspections. The neglect of some critical TMLs is common since the field experts have to analyze a vast amount of data from different DSMs. The introduction of artificial neural networks to replace the analysis part of the field experts' work process increases not only the quality of the analysis but also the reliability of the identification of critical TMLs which have a possibility of failure in the operation. Moreover, the neural network system can link with the DSMs and condition monitoring data to generate a system that accurately makes TML prioritization for the inspection planning.

Acknowledgements. The authors would like to thank Roy Martin Zydeman and the in-service inspection planning team in Aker Solutions Offshore Partner, Norway, for their support in this research study.

\section{References}

1. Alvarado, M., Rodriguez-Toral, M., Rosas, A., Ayala, S.: Decision-making on pipe stress analysis enabled by knowledge-based systems. Knowledge and Information Systems 12, 255-278 (2007)

2. API RP 580. Risk Based Inspection, 1st edn. American Petroleum Institute (2002)

3. API RP 58. Risk Based Inspection Technology, 2nd edn. American Petroleum Institute (2008)

4. Becraft, W.R., Lee, P.L.: An integrated neural network/expert system approach for fault diagnosis. Computers \& Chemical Engineering 17, 1001-1014 (1993)

5. DNV RP G101. G101: Risk based inspection of offshore topside static mechanical equipment, Det Norske Veritas (DNV), Norway (2010)

6. DNV RP O501. Recommended practice DNV RP O501: Erosive Wear in Piping Systems. Det Norske Veritas (DNV), Norway (2007)

7. Ferre, D., Ferschneider, G., Pauchon, C.: Method for modelling multiphase flows in pipelines. U.S. Patent No. 5,550,761. U.S. Patent and Trademark Office, Washington, DC (1996)

8. Kahkonen, T., Smolander, K.E.: Integration. ICEIS, 23 (2013)

9. Knapp, G.M., Wang, H.P.: Machine fault classification: a neural network approach. International Journal of Production Research 30, 811-823 (1992)

10. Nesic, S.: Key issues related to modelling of internal corrosion of oil and gas pipelines - A review. Corrosion Science 49, 4308-4338 (2007)

11. Nesic, S., Li, H., Huang, J., Sormaz, D.: An open source mechanistic model for $\mathrm{CO} 2$ / H2S corrosion of carbon steel. NACE International, Corrosion 2009, Paper No. 09572 (2009)

12. NORSOK M-506, NORSOK Standard M-506: CO2 corrosion rate calculation model. Standards Norway, Lysaker, Norway (2005)

13. NORSOK Z-008. Risk based maintenance and consequence classification. Rev. 3, Standards Norway, Lysaker, Norway (2011) 
14. Ratnayake, R.M.C.: Challenges in inspection planning for maintenance of static mechanical equipment on ageing oil and gas production plants: The state of the art. In: Proceedings of the ASME 31st International Conference on Ocean, Offshore and Arctic Engineering. Paper no. OMAE2011-49050 (2012a)

15. Ratnayake, R.M.C.: A decision model for executing plant strategy: maintaining the technical integrity of petroleum flowlines. International Journal of Decision Sciences, Risk and Management (IDJRSM) 4(1/2), 1-24 (2012b)

16. Ratnayake, R.M.C.: Modeling of asset integrity management process: A case study for computing operational integrity preference weights. International Journal of Computational Systems Engineering (IJCSysE) 1(1), 3-12 (2012c)

17. Ratnayake, R.M.C.: Utilization of piping inspection data for continuous improvement: a methodology to visualize coverage and finding rates. In: Proceedings of the ASME 32nd International Conference on Ocean, Offshore and Arctic Engineering, paper no. OMAE2013-10025 (2013)

18. Ratnayake, R.M.C.: Application of a fuzzy inference system for functional failure risk rank estimation: RBM of rotating equipment and instrumentation. International Journal of Loss Prevention in the Process Industries 29, 216-224 (2014)

19. Ratnayake, R.M.C., Markeset, T.: Maintaining technical integrity of petroleum flow lines on offshore installations: A decision support system for inspection planning. In: Proceedings of the ASME 2010 29th International Conference on Ocean, Offshore and Arctic Engineering. Paper no. OMAE2010-20035 (2010), doi:10.1115/OMAE2010-20035

20. Ratnayake, R.M.C., Samarakoon, S.M.S.M.K., Markeset, T.: Maintenance integrity: Managing flange inspections on aging offshore production facilities. In: Proceedings of the ASME 30th International Conference on Ocean, Offshore and Arctic Engineering. Paper no. OMAE2011-49050, pp. 19-32 (2011), doi:10.1115/OMAE2011-49050

21. Seneviratne, A.M.N.D.B., Ratnayake, R.M.C.: In-service inspection of static mechanical equipment: Use of a fuzzy inference system for maintaining the quality of an inspection program. In: Proceedings of the IEEE International Conference Industrial Engineering and Engineering Management (IEEM), Thailand (2013)

22. Srinivasan, S., Sueth, M.: Real time risk-based asset management - A framework for sustainable asset integrity solutions. In: Reliability and Maintenance Conference and Exhibition, Denver, pp. 416-431 (2011)

23. Valle, A.: Multiphase pipeline flows in hydrocarbon recovery. Multiphase Science and Technology 10 (1998) 